\title{
Staphylococcus epidermidis
}

National Cancer Institute

\section{Source}

National Cancer Institute. Staphylococcus epidermidis. NCI Thesaurus. Code C86757.

A species of facultatively anaerobic, Gram positive, cocci shaped bacteria in the phylum Firmicutes. This species is positive for catalase, urease, and alkaline phosphatase and negative for coagulase and oxidase. It can ferment glucose, fructose, maltose, sucrose, glycerol, mannose, lactose, and turanose but not arabinose, mannitol, xylose, cellobiose, xylitol, rhamnose or trehalose. S. epidermidis is a commensal human skin org anism and can be a human pathogen causing sepsis or endocarditis in patients with implants or immunocompromised individuals. 